IOSR Journal of Pharmacy

e-ISSN: 2250-3013, p-ISSN: 2319-4219, www.iosrphr.org

Volume 2 Issue 6 ||| Nov-Dec. 2012 ||| PP.17-23

\title{
Thermal and Spectroscopic Studies on Nizatidine-PVP mixture
}

\author{
Sailaja Urpayil ${ }^{1 *}$, M. Shahin Thayyil ${ }^{2}$

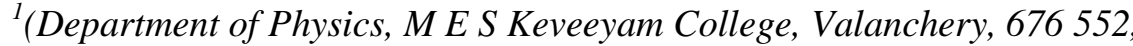 \\ Malappuram, Kerala, INDIA) \\ ${ }^{2}$ (Department of Physics, University of Calicut, 673 635, Kerala, INDIA)
}

\begin{abstract}
Nizatidine is commonly used in the treatment of peptic ulcer disease (PUD) and gastroesophageal reflux disease (GERD). The interaction between the drug and the additives is an important issue in the stabilization of the amorphous Active Pharmaceutical Ingredients (APIs). Interaction between Nizatidine and PVP was studied with the help of differential scanning calorimetry (DSC) and Fourier Transform Infrared Spectroscopy (FTIR). Single glass transition peak in DSC thermogram shows the miscibility of the drug-PVP and shifting of $C=O$ band of Nizatidine-PVP binary to lower wavenumber shows strong hydrogen bonding between the amino group of Nizatidine and carbonyl group of monomeric unit of PVP compared to those observed in the pure crystalline Nizatidine. X-ray powder diffraction (XRPD) confirms the amorphous nature of $P V P$.
\end{abstract}

Keywords-Bioavailability, differential scanning calorimetry, Fourier transform infrared spectroscopy, Nizatidine, solubility, solid dispersion.

\section{INTRODUCTION}

Crystallization of amorphous drugs is an important matter during processing and storage. During crystallization the drug molecules becomes arranged in a three dimensional order. Thermodynamical instability is the main reason why the amorphous drugs have been not commonly used to improve the bioavailability even though they are economical and easy to prepare [1]. The stabilization of the drugs in the amorphous state can be achieved by addition of suitable excipients which is thermodynamically miscible with the APIs.

Nizatidine is selected as the model compound for the present study. Nizatidine is a histamine $\mathrm{H}_{2}$ receptor antagonist that inhibits stomach acid production and commonly used in the treatment of peptic ulcer disease (PUD) and gastroesophageal reflux disease (GERD). It is also used to control weight gain associated with some antipsychotic medication. Its bioavailability is about 70\% [2]. PVP K-30 is selected as the excipient and it is a polymer with a large number of monomers, each possessing a $-\mathrm{C}=\mathrm{O}$ group, which shows inhibitory effect on the crystallization of drugs when it is mixed with the drugs. PVP showed the strongest effect among K$15, \mathrm{~K}-30$, and K-90. When the drug and PVP is dissolved in a solvent and the solvent is evaporated in vacuum and the drug loses its crystal structure in PVP matrix and forms co-precipitate. Co-precipitate is formed due to the inhibitory effect of PVP on the crystallization of the drug [3].

To understand the miscibility between the drug and the excipient we have used differential scanning calorimetry (DSC). DSC is an effective tool to study the thermal properties of pharmaceuticals in the crystalline and amorphous form $[4,5,6]$. Addition of PVP increased the glass transition temperature $\left(T_{g}\right)$ of Nizatidine. Association of hydrogen bond formation was evaluated by using IR spectroscopy and observed a strong bond formation between the Nizatidine and PVP. This gives an insight to inhibitory effect of PVP on the crystallization of Nizatidine in the amorphous state for getting maximum shelf life stability during processing and storage.

\subsection{Nizatidine}

\section{MATERIALS AND METHODS}

Nizatidine, an off white crystalline powder was purchased from Sigma Aldrich (Fluka). Nizatidine is chemically described as $\mathrm{N}$-(2-[(dimethylamino) methyl]-N-methyl-2-nitroethane-1, 1-diamine. Its empirical formula is $\mathrm{C}_{12} \mathrm{H}_{21} \mathrm{~N}_{5} \mathrm{O}_{2} \mathrm{~S}_{2}$ and molecular weight is $331.46 \mathrm{~g}$. mol ${ }^{-1}$ [7]. The chemical structure is presented in "Fig.1". The purchased material was used without further purification. 
<smiles>CN/C(=C\[N+](=O)[O-])NCCSCc1csc(CN(C)C)n1</smiles>

Figure. 1 The chemical structure of Nizatidine.

\subsection{Polyvinylpyrrolidone K-30 (PVP K-30).}

PVP, a white powder obtained from Pankaj Sales Agencies, Mumbai. IUPAC name of PVP is poly (2oxopyrrolidin1-yl ethylene) and consists of linear polymers of 1-vinylpyrrolidin 2-one. Its empirical formula is $\left(\mathrm{C}_{6} \mathrm{H}_{9} \mathrm{NO}\right)_{\mathrm{n}}$ and molecular weight is $(111.2)_{\mathrm{n}}$ [8]. The chemical structure is presented in "Fig.2". The purchased material was used without further purification.

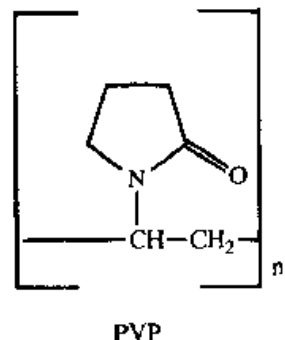

\subsection{Nizatidine-PVP solid dispersions}

Figure. 2 The chemical structure of PVP

The solid dispersions of Nizatidine and PVP were prepared by dissolving the components in methanol (Nizatidine-PVP (90:10 w/w) in $10 \mathrm{ml}$ methanol) so as to allow their mixing at a molecular level; the solvent was removed under heat and vacuum using a rotary evaporator. Residual solvent was removed by drying under vacuum at room temperature for 24 hours. After preparation the solid dispersions were analysed by DSC, FTIR [9-12].

\subsection{X-Ray Powder Diffraction (XRPD)}

X-ray diffraction technique was applied to study the nature of the samples. Nizatidine and PVP were analysed by XRPD. A XPERT-PRO diffractometer system with a rotating anode $\mathrm{Cu} \mathrm{K} \alpha$ radiation $\left(1.5406 \mathrm{~A}^{0}\right)$ was used and scans were taken over a $2 \theta$ range of $5^{\circ}-100^{\circ}$.

\subsection{Differential Scanning Calorimetry (DSC) \\ 2.5.1 Nizatidine}

Calorimetric response of the sample was measured using a DSC instrument $\left(821^{\mathrm{e}}\right.$ Metler-Toledo $\mathrm{GmbH})$ operating with $\mathrm{STAR}^{\mathrm{e}}$ software version 9.1 and equipped with an intra cooler. The instrument was calibrated by using indium. The sample $5.1240 \mathrm{mg}$ were analyzed under dry nitrogen purge $(50 \mathrm{ml} / \mathrm{min})$ in a sealed and pinhole aluminum pan.

The sample is heated from room temperature to $147^{\circ} \mathrm{C}$ and held for 5 minutes, then the sample is cooled to ($50^{\circ} \mathrm{C}$ ) and held for 15 minutes, and then the sample is again heated to $152^{\circ} \mathrm{C}$ a constant heating and cooling rate of $10^{\circ} \mathrm{C} / \mathrm{min}$ is used. Thermograms were collected during heating. Melting point was determined as the onset of the endothermic peak, where as glass transition temperature is measured as the onset of the glass transition.

\subsubsection{PVP}

DSC experiment was done by taking sample of $5.3600 \mathrm{mg}$ and analyzed under dry nitrogen purge $(50 \mathrm{ml} / \mathrm{min})$ in a sealed and pinhole aluminium pan. The sample is heated from room temperature to $250^{\circ} \mathrm{C}$ and a heating rate of $10^{\circ} \mathrm{C} / \mathrm{min}$ is used. $\mathrm{T}_{\mathrm{g}}$ was measured as the onset of the glass transition.

2.5.3 Nizatidine-PVP mixture

The sample is heated from room temperature to $147^{\circ} \mathrm{C}$ and held for 5 minutes, then the sample is cooled to ($50^{\circ} \mathrm{C}$ ) and held for 15 minutes, and then the sample is again heated to $152^{\circ} \mathrm{C}$ a constant heating and cooling rate of $10^{\circ} \mathrm{C} / \mathrm{min}$ is used. $\mathrm{T}_{\mathrm{m}}$ and $\mathrm{T}_{\mathrm{g}}$ were measured as the onset values.

\subsection{Fourier Transform Infrared (FTIR) Spectroscopy}

IR spectroscopy is applied to study the nature of hydrogen bond formation in the samples. The instruments used are FTIR (Nicolet instruments corporation USA, Model MAGNA) for crystalline and FTIR microscope (Perkin Elmer, model: Synthesis Monitoring System) for amorphous samples.

\subsection{Solubility}

Solubility test of the crystalline and amorphous Nizatidine was done in methanol at $37^{\circ} \mathrm{C}$. It is found that the amorphous form is having better solubility than that of the crystalline form. 
3.1 XRPD Results

\section{RESULTS AND DISCUSSION}

\subsubsection{Nizatidine.}

The sharp Bragg's diffraction peaks in "Fig.3" confirm the crystalline nature of Nizatidine.

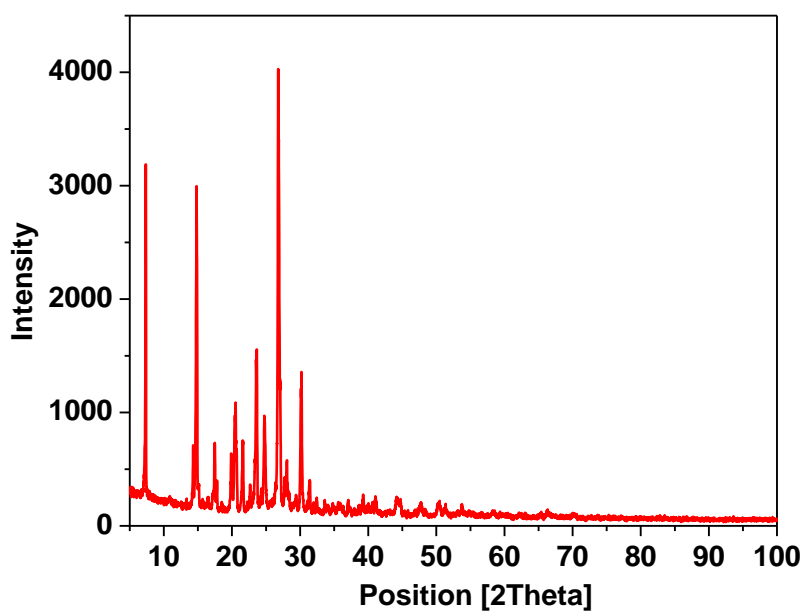

Figure. 3 X-Ray powder diffraction pattern of crystalline Nizatidine

\subsubsection{XRPD Result of PVP}

Diffraction patterns for PVP is presented in "Fig .4", very broad peaks observed in "Fig. 4", suggest that there is no diffraction, that is no long- range three-dimensional molecular order for PVP. This confirms the amorphous nature of the sample.

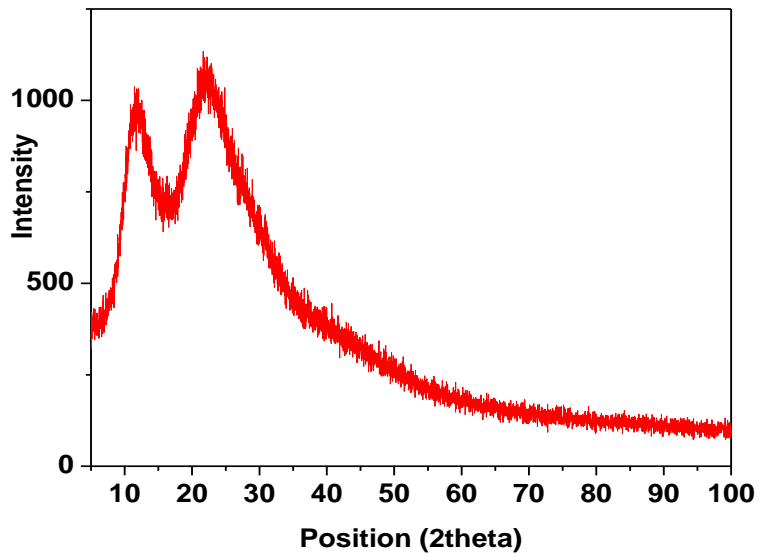

Figure. 4 X-Ray powder diffraction pattern of PVP

\subsection{Thermal Transitions Studies by DSC}

\subsubsection{Nizatidine}

The thermal transition study of Nizatidine by DSC shows the onset glass transition observed at a temperature $\left(\mathrm{T}_{\mathrm{g}}\right)=283.46 \mathrm{~K}$, and the onset melting of the sample is observed at $405.36 \mathrm{~K}$ which is melting temperature $\mathrm{T}_{\mathrm{m}}$ of the sample. No crystallization was observed during cooling and heating treatment of this sample. These results are in good agreement with those reported by Pajula et al., [13]. Thermogram is shown in "Fig.5". 


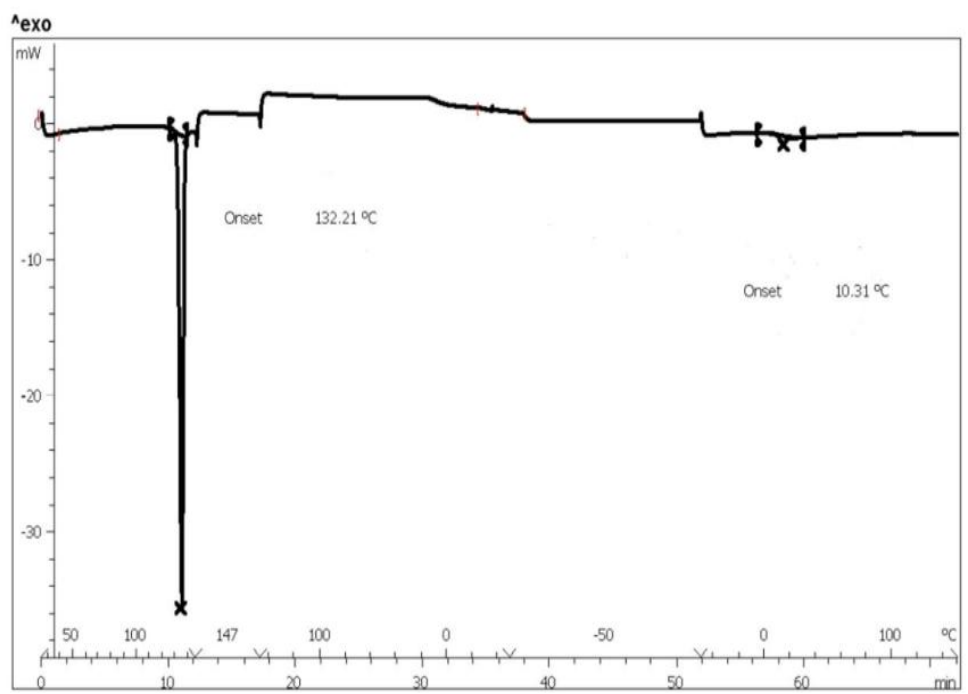

Figure. 5 DSC thermogram of Nizatidine obtained during heating/cooling with $10^{\circ} \mathrm{C} / \mathrm{min}$. Heating of the sample yields $\mathrm{T}_{\mathrm{m}}=405.36 \mathrm{~K}$ as the onset melting temperature. Subsequent cooling of the melt from 420.15 $\mathrm{K}$ down to $223.15 \mathrm{~K}$. Following heating of the vitrified Nizatidine to a temperature higher than $\mathrm{T}_{\mathrm{m}}$. The onset glass transition temperature obtained on heating is $\mathrm{T}_{\mathrm{g}}=283.46 \mathrm{~K}$ : at higher temperature there is no evidence of crystallization.

\subsubsection{PVP}

From thermal transition studies of PVP shows onset value of $\mathrm{T}_{\mathrm{g}}$ as $433.95 \mathrm{~K}$ as shown in "Fig.6". This value is found to be in close agreement with the value reported by Gupta et al., [10].

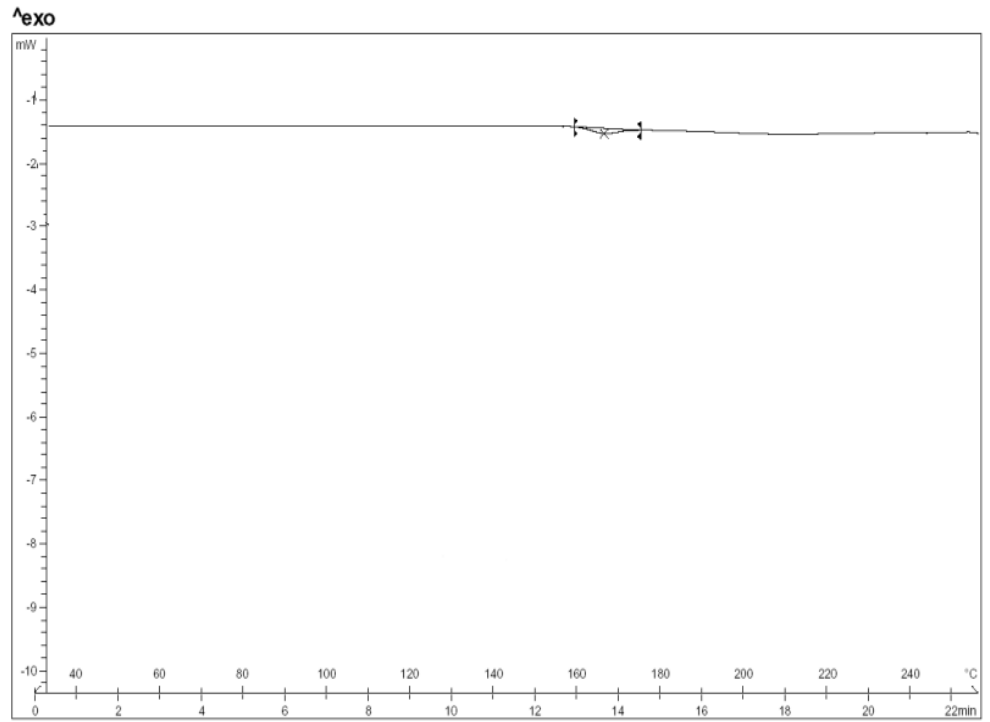

Figure. 6 DSC thermogram of PVP obtained during heating with $10^{\circ} \mathrm{C} / \mathrm{min}$. The onset glass transition temperature obtained on heating is $\mathrm{T}_{\mathrm{g}}=433.95 \mathrm{~K}$.

\subsubsection{Nizatidine-PVP Solid dispersion}

The solid dispersion of Nizatidine and PVP were prepared by dissolving the components in methanol, residual solvent was removed by solvent evaporation technique. After preparation the solid dispersions were analyzed by DSC. The $\mathrm{T}_{\mathrm{g}}$ of amorphous Nizatidine and PVP was observed as 283.46 K and 433.95 K. Molecular level mixtures of these two components can be expected to exhibit $\mathrm{T}_{\mathrm{g}}$ value intermediate of their original values, with a higher $\mathrm{T}_{\mathrm{g}}$ for amorphous Nizatidine-PVP shows the antiplasticization of PVP. A stronger bonding between unlike molecules raises the $T_{g}$. The mixture shows a $T_{g}$ of $301.26 \mathrm{~K}$ during cooling from the melt and $284.02 \mathrm{~K}$ on heating from the glassy state. Melting endotherm is shifted to a lower value of $404.11 \mathrm{~K}$ "Fig.7". The shift in the endotherm of Nizatidine in the presence of PVP indicates the interaction between the two species $[14,10,12]$. No sign of crystallization was observed during the heating-cooling treatment.

Nizatidine-PVP binary systems showed single $T_{g}$, the value of which was between those of the individual components, there by establishing the drug-additive miscibility. 


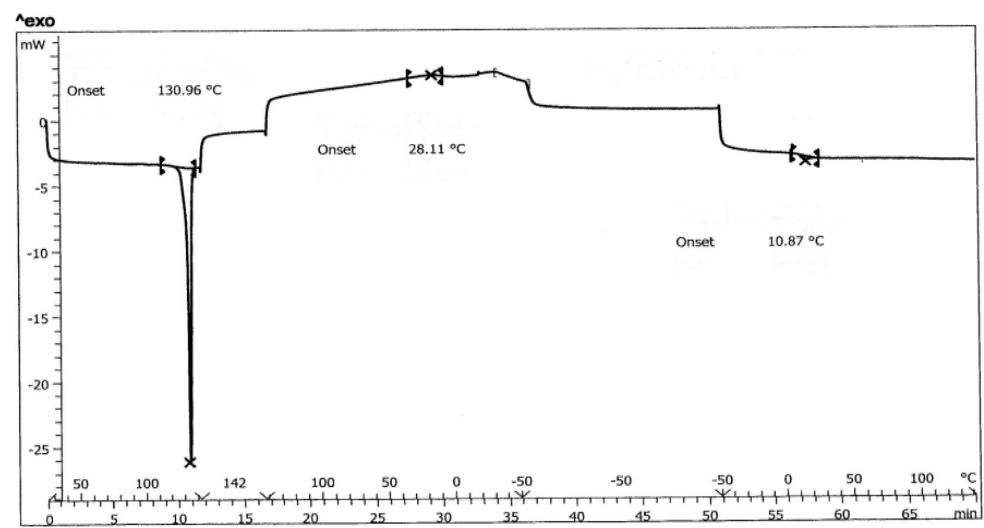

Figure. 7 DSC thermogram of Nizatidine-PVP obtained during heating/cooling with $10^{\circ} \mathrm{C} / \mathrm{min}$. Heating of the sample yields $\mathrm{T}_{\mathrm{m}}=404.11 \mathrm{~K}$ as the onset melting temperature. Subsequent cooling of the melt from $420.15 \mathrm{~K}$ down to $223.15 \mathrm{~K}$, Followed by heating of the vitrified Nizatidine-PVP to a temperature higher than $\mathrm{T}_{\mathrm{m}}$. The onset glass transition temperature obtained on heating is $\mathrm{T}_{\mathrm{g}}=284.02 \mathrm{~K}$ : at higher temperature there is no evidence of crystallization.

\subsection{Spectral characterization}

\subsubsection{Crystalline and Amorphous Nizatidine}

Infrared spectra of Nizatidine "Fig. 8" showed different strengths of hydrogen bonding. Nizatidine showed two peaks, one corresponds to secondary amino group and the other for nitro group. In the crystalline form amino peak corresponds to $3277 \mathrm{~cm}^{-1}$. In the amorphous form the amino peak shifts to lower wavenumber $3261 \mathrm{~cm}^{-1}$ showing strong hydrogen bond formation in the amorphous phase. The peak position of the nitro group of crystalline phase is at $1620 \mathrm{~cm}^{-1}$ and in amorphous phase the peak shift to a lower wavenumber of $1611 \mathrm{~cm}^{-1}$. Nitro compounds, nitrates, and nitramines contain an $\mathrm{NO}_{2}$ group. Each class shows absorption due to asymmetrical and symmetrical stretching of the $\mathrm{NO}_{2}$ group. Asymmetrical absorption results in a strong band in the $1661-1499 \mathrm{~cm}^{-1}$ region: symmetrical absorption occurs in the region between $1389-1259 \mathrm{~cm}^{-1}$. In Nizatidine the asymmetrical absorption in the nitro region was found to be strong in crystalline as well as in the amorphous phase [15].
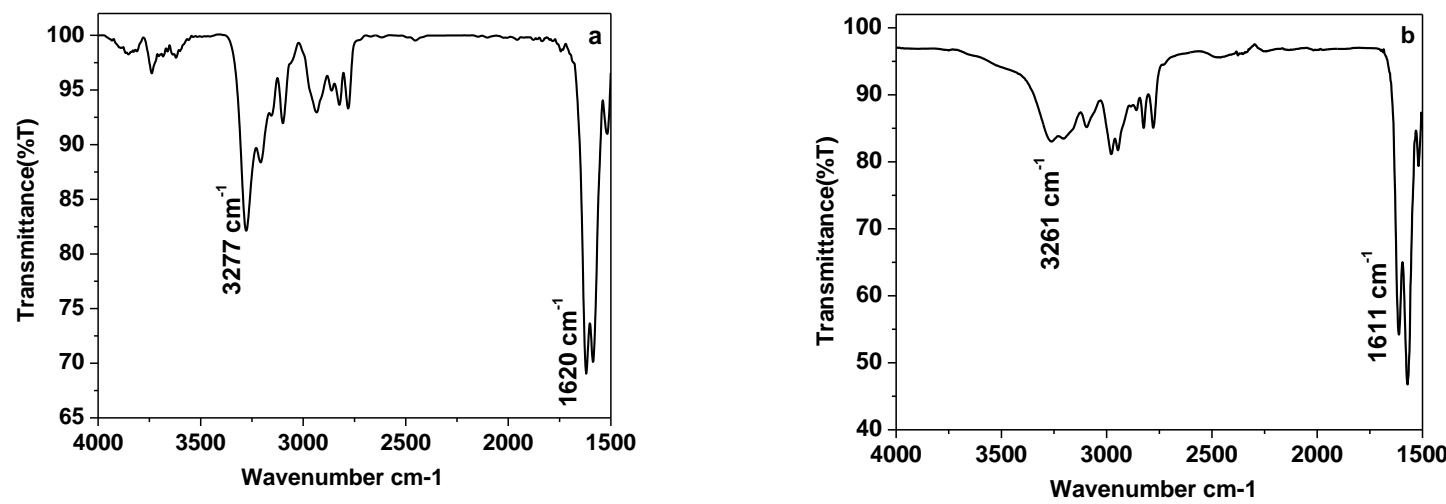

Figure. 8 FTIR spectra in nitro and amino stretching vibration region (a) crystalline, (b) amorphous Nizatidine.

\subsubsection{Spectral variations in PVP}

The FTIR spectrum of PVP showed a strong band at $1663 \mathrm{~cm}^{-1}$ characteristic of $\mathrm{C}=\mathrm{O}$ stretching vibration region as in "Fig. 9". 


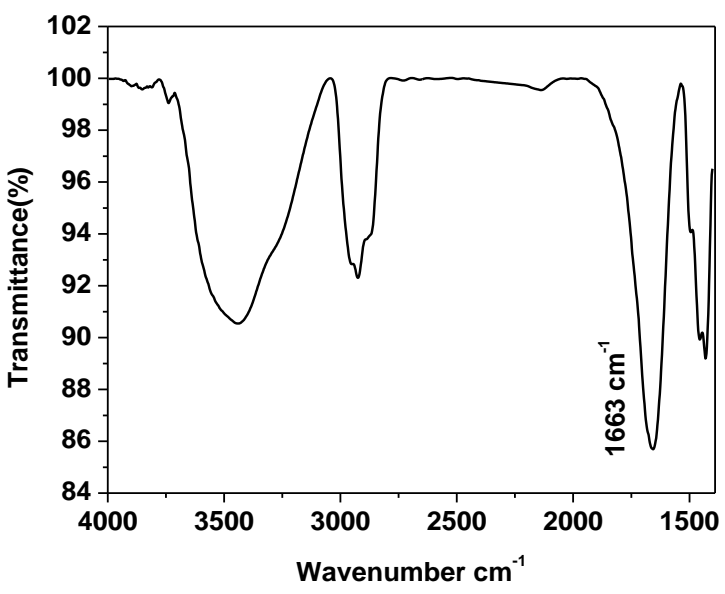

Figure. 9 FTIR spectra in $\mathrm{C}=\mathrm{O}$ stretching vibration region of $\mathrm{PVP}$.

\subsubsection{Spectral variations in Nizatidine-PVP Solid dispersion}

IR spectra of Nizatidine-PVP binary systems is presented in "Fig.10" and showed different strengths of hydrogen bonding. Nizatidine-PVP showed three peaks corresponds to one for secondary amines, second one for nitro group and the third for $\mathrm{C}=\mathrm{O}$ of the PVP. The amino peak corresponds to $3273 \mathrm{~cm}^{-1}$. Nitro group the peak position is at $1585 \mathrm{~cm}^{-1}$. Nitro compounds, nitrates, and nitramines contain an $\mathrm{NO}_{2}$ group. Each class shows absorption due to asymmetrical and symmetrical stretching of the $\mathrm{NO}_{2}$ group. Asymmetrical absorption results in a strong band in the 1661-1499 $\mathrm{cm}^{-1}$ region: symmetrical absorption occurs in the region between 1389$1259 \mathrm{~cm}^{-1}$. In Nizatidine-PVP K-30 the asymmetrical absorption in the nitro region was found to be strong. The Nizatidine-PVP showed the shift of the $\mathrm{C}=\mathrm{O}$ stretching vibration band from $1663 \mathrm{~cm}^{-1}$ to $1621 \mathrm{~cm}^{-1}$. This result clearly indicate the $\mathrm{H}$-bonding affinity between the $\mathrm{N}-\mathrm{H}$ group of Nizatidine and $\mathrm{C}=\mathrm{O}$ group of PVP. The existence of H-bonding in the binary can have a strong implication on limiting the molecular mobility of the drug in the amorphous phase [15]. Table 1 shows the peak positions of Nizatidine and PVP at different stretching vibration regions.

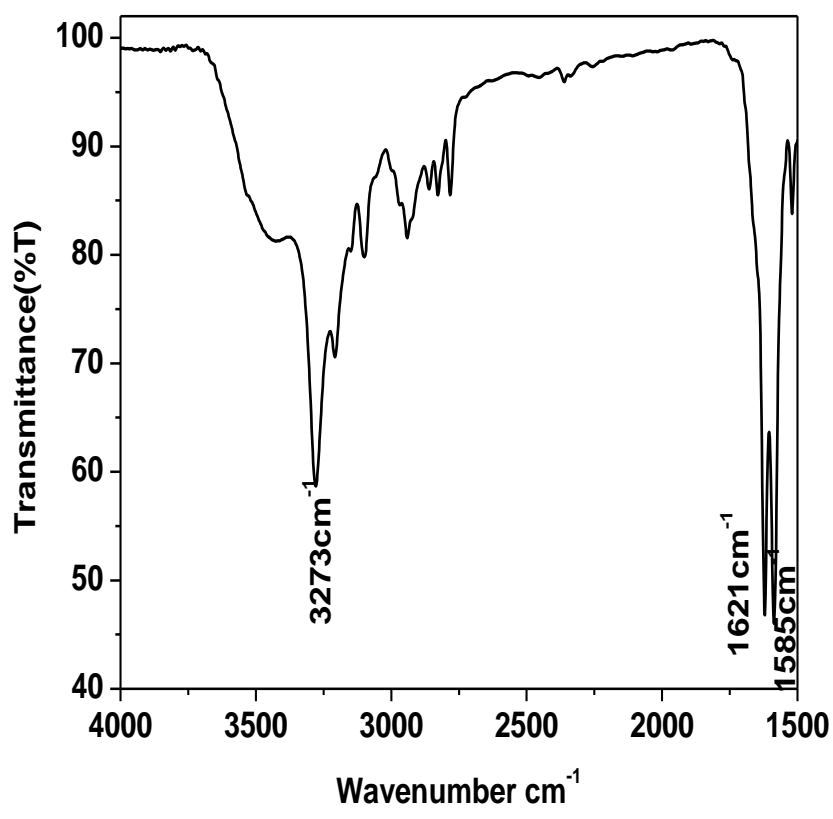

Figure.10. FTIR spectra in $\mathrm{C}=\mathrm{O}$ stretching vibration region for Nizatidine-PVP solid dispersions. 
Table.1 IR Peak Positions for the $\mathrm{NH}, \mathrm{NO}_{2}$ and $\mathrm{C}=\mathrm{O}$ Stretching Vibrations for Crystalline and Amorphous Nizatidine.

\begin{tabular}{|c|c|c|c|c|c|c|}
\hline & \multicolumn{2}{|c|}{$v \mathrm{NH}\left(\mathrm{cm}^{-1}\right)$} & \multicolumn{2}{|c|}{$v \mathrm{NO}_{2}\left(\mathrm{~cm}^{-1}\right)$} & \multicolumn{2}{|c|}{$v \mathrm{C}=\mathrm{O}\left(\mathrm{cm}^{-1}\right)$} \\
\hline Compound & Crystalline & Amorphous & Crystalline & Amorphous & Crystalline & Amorphous \\
\hline $\begin{array}{l}\text { Nizatidine } \\
\text { PVP }\end{array}$ & 3277 & 3261 & 1620 & 1611 & & 1663 \\
\hline $\begin{array}{l}\text { Nizatidine-PVP } \\
\text { (Solid dispersion) }\end{array}$ & 3273 & & 1585 & & 1621 & \\
\hline
\end{tabular}

\section{CONCLUSION}

DSC study reveals that Nizatidine is non-crystallizing compound and the mixture of Nizatidine and PVP shows single glass transition during cooling and heating treatment proves the miscibility of drug and the polymer. Using the IR spectral data the hydrogen bond strengths and patterns in Nizatidine can be elucidated. The shifting of amino peak to the lower wavenumber shows strong hydrogen bond formation in the amorphous phase and nitro group forms strong asymmetric absorption bands in both the phases. X-ray diffraction techniques indicate the amorphous nature of PVP. The IR spectrum of the solid dispersion of Nizatidine-PVP showed strong hydrogen bonding between the drug and the polymer, which leads to the inhibitory effect of PVP on the crystallization of the drug. Solubility test at $37^{\circ} \mathrm{C}$ proves greater solubility for amorphous phase.

\section{ACKNOWLEDGMENTS}

The authors wish to thank CIL, NIPER Mohali, Punjab, Centre for Medicinal Plants Research (CMPR), Arya Vaidya Sala, Kottakkal, Kerala, India for providing experimental facility. Sailaja Urpayil acknowledges University Grants Commission, Government of India for the award of a research fellowship under the Faculty Improvement Program (FIP).

\section{REFERENCES}

Kaminski K, Kaminska E, Adrjanowicz K, Grzybowiska K, Wlodarczyk P, Paluch M, Burian A, Ziolo J, Lepek P, Mazgalski J, Sawicki W. Dielectric Relaxation Study on Tramadol Monohydrate and Its Hydrochloride Salt, J. Pharm. Sci. 2009, 99, 94-106.

[2]. http://www.drugbank.ca/drugs/DB00585.

[3]. Sekikawa H, Nakano M, Arita T. Inhibitory Effect of Polyvinylpyrrolidone on the Crystallization of Drugs, Chem. Pharm. Bull. 1978, 26(1), 118-126.

[4]. Hancock B C, Parks M. What is the true solubility advantage for amorphous pharmaceuticals? Pharma research. 1999, 17, 397-404.

[5]. Sailaja U, Shahin Thayyil M. Dielectric and Spectroscopic Investigations of Amorphous Captopril, IOSR J. Pharm. 2012, 2, 479-484. ISSN: 2250-3013.

[6]. Crowley KJ, Zografi G. Use of thermal methods for predicting glass-former fragility. Ther. Chimi. Acta, 2001, 380, 79-93.

[7]. British Pharmacopoeia 2009.

[8]. Indian Pharmacopoeia, 2007.

[9]. Aso Y, Yoshika S, Kojima S. Molecular Mobility-Based Estimation of The crystallization Rates of Amorphous Nifedipine and Phenobarbital in Poly (vinylpyrrolidone) Solid Dispersion. J.Pharm.Sci. 2004, 93, 384-391.

[10]. Gupta P, Thilagavathi R, Chakraborti A K, Bansal A K. Role of Molecular Interaction in Stability of CelecoxibPVP Amophous Systems, Mol. Pharm. 2005, 2, 384-391.

[11]. Shmeis R A, Wang Z, Krill S. A mechanistic investigation of an amorphous pharmaceutical and its solid dispersions, Part II : Molecular mobility and activation thermodynamic parameters, Pharma Research, 2004, 21, 031-2038.

[12]. Taylor L S, Zografi G. Spectroscopic characterization of interactions between PVP and indomethacin in amorphous molecular dispersions, Parma research, 1997, 14, 1691-98.

[13]. Pajula K, Taskinen M, Lehto VP, Ketolainen J, Korhonen O. Predicting the Formation and Stability of Amorphous Small Molecule Binary Mixtures from 99 Computationally Determined Flory-Huggins Interaction Parameter and Phase Diagram. Mol. Pham, 2010, 7, 79-804.

[14]. Aso Y, Yoshika S, Kojima S. Molecular Mobility-Based Estimation of The crystallization Rates of Amorphous Nifedipine and Phenobarbital in Poly (vinylpyrrolidone) Solid Dispersion. J.Pharm.Sci. 2004, 93, 384-391.

[15]. Silverstein R.M, Bassler G.C, Morrill T.C. Spectrometric Identification of Organic Compounds. Fifth edition. John Wiley \& Sons, Singapore 1991. 